\title{
The efficacy of diatomaceous earth in mixed formulation with other dusts and an insecticide against the pulse beetles, Callosobruchus chinensis $\mathrm{L}$. and Callosobruchus maculatus (F.)
}

\author{
Shah Hussain Ahmad Mahdi* and M. Khalequzzaman \\ Department of Zoology, University of Rajshahi, Rajshahi-6205, Bangladesh.
}

\begin{abstract}
Effectiveness of diatomaceous earth (DE) and other inert dusts (kaolin powder, paddy husk ash, coal ash, alluvial soil, china clay) and a dust formulation insecticide carbaryl have been tested on the pulse beetles Callosobruchus chinensis L. and C. maculatus (F.). The bioassay of the dusts was done on adult beetles by mixing them with normal food (lentil and black gram seeds). The $\mathrm{LD}_{50}$ of the combined doses of mixtures for $C$. chinensis have been calculated as 12703.57 and $859.36 \mathrm{ppm}$ for DE+ kaolin powder; 2432.78 and 274.00 ppm for DE+ paddy hush ash; 3430.036 and 426.16 ppm for DE+ coal ash; 12563.47 and 652.29 ppm for DE+ alluvial soil; 2242.81 and $325.76 \mathrm{ppm}$ for DE+ china clay; and 21.33 and 14.45 ppm for DE+ carbaryl after 24 and $48 \mathrm{~h}$ after treatment respectively. The $\mathrm{LD}_{50}$ of combined doses of different mixtures for $C$. maculatus have been calculated as 3640.65 and 503.74 ppm for DE+ kaolin powder; 54946.68 and 987.2394 ppm for DE + paddy hush ash; 61029.04 and 3229.436 ppm for DE+ coal ash; 61029 and $4265.599 \mathrm{ppm}$ for DE+ alluvial soil; 4648.786 and $642.278 \mathrm{ppm}$ for DE+ china clay; and 24.12017 and 15.47023 ppm for DE+ carbaryl after 24 and $48 \mathrm{~h}$ after treatment respectively. The co-toxicity coefficient has been calculated and all ratios showed synergistic action. The highest co-toxicity coefficient was recorded as 88885.15 and 92107.22 in DE+ carbaryl at 24 and $48 \mathrm{~h}$ after treatment for C. chinensis and 78615.55 and 86004.88 in DE+ carbaryl at 24 and $48 \mathrm{~h}$ after treatment for C. maculatus.
\end{abstract}

Key words: Diatomaceous earth, Callosobruchus chinensis, C. maculatus, inert dust, carbaryl.

* Corresponding author's e-mail: mahdi_ru@yahoo.com

\section{Introduction}

Inert dusts, especially DE dusts and silica gels, are suitable for disinfesting empty storage facilities and for grain treatment (Aldryhim, 1990). Their use is more appealing in view of the widespread development of resistance in storedproduct insects to conventional pesticides. Fields (2000) studied that the minimum effective rate of dust needed for suppression of progeny production of bruchid beetles $50 \%$ less in mixed form with other dusts than that needed for complete mortality used alone.

Admixture of dust formulations of insecticides with grain is a widely used method of protection against stored product pests and has particular advantages when used to treat small batches for local storage (LaHue, 1978). In some cases insecticides are supplied by manufacturers as dust concentrates for dilution with locally available mineral bases; in other cases formulation is carried out in the user country using local mineral carriers and imported technical grade insecticide. The addition of suitable stabilizing agents is usually necessary to prevent rapid decomposition of the insecticide on the mineral surface, and a small proportion of amorphous silica is sometimes added to dust concentrates as an anti-caking agent.

The integration of non-chemical control methods can mitigate problems related to residues in food and pest resistance by overuse of these products (Beckel et al., 2004). The manipulation of grain temperature and the use of inert dusts such as diatomaceous earth are examples of promising non-chemical methods for the integrated management of insect pests of stored products (Flinn, 1998; Flinn \& Hagstrum, 2002; da Conceição et al., 2012). Diatomaceous earth is derived from sediment diatomaceous alga shell, and when in contact with the insects causes the removal of the wax layer of the cuticle, causing its death by desiccation (Korunic, 1998).

Diatomaceous earth mixed with grain via dusting or spraying, controls most of the pests effectively. This product works on larvae and adult insects, clinging to their bodies as they move on the surface or within the treated grain mass (Alves et al., 2006). Moreover, it presents some advantages such as low toxicity to mammals and environment; it does not leave harmful residues in the treated product; it is effective against insect species resistant to insecticides, and it is persistent and stable at high and low temperatures (Collins, 2006).

However, studies are needed on the toxicity of diatomaceous earth in combination for populations of insect pests of stored products with 
different standard of susceptibility to the insecticides currently in use. These studies are important because populations of the same species with different genotypes may show different responses to the same treatment (McKenzie, 1996; Li et al., 2007).

Inert dusts, especially DE dusts and silica gels are suitable for disinfesting empty storage facilities and for grain treatment. Their use is more appealing in view of the widespread development of resistance in stored-product insects to conventional pesticides. On grain, different treatment techniques (treating partial layers) should be explored. Locally available different inert dusts are easily available and initiatives should be given to develop insecticides with these materials. Keeping these in mind the present study was undertaken to find out the toxicity of DE and some other inert dusts on the adult pulse beetles, $C$. chinensis and $C$. maculatus.

\section{Materials and Methods Test Insects}

The pulse beetles $C$. chinensis and $C$. maculatus were collected from Shaheb Bazar, Rajshahi. Mass cultures were maintained in earthen pots and sub-cultures in glass jars $(500 \mathrm{ml})$ or beakers $(500$ $\mathrm{ml}$ ) with the food medium in the Crop Protection and Toxicology Laboratory, Department of Zoology, University of Rajshahi, Bangladesh. All the equipments were kept in an oven for sterilization, about six hours at $60^{\circ} \mathrm{C}$. Lentil (Lens culinaris Medic.) and black gram (Vigna mungo (L.)) seeds were used as food medium for $C$. chinensis and C. maculatus respectively through the experiment. A large number of beetles were thus reared for continuous supply of the newly emerged adults.

\section{Diatomaceous earth and others dusts}

SilicoSecs was obtained from Agrinova $\mathrm{GmbH}$ (Germany). SilicoSec is a relatively new DE formulation of freshwater origin, and contains approx. $92 \% \mathrm{SiO}_{2}, 3 \% \mathrm{Al}_{2} \mathrm{O}_{3}, 1 \% \mathrm{Fe}_{2} \mathrm{O}_{3}$, and $1 \%$ $\mathrm{Na}_{2} \mathrm{O}$ (McLaughlin, 1994). A dry lump of kaolin was purchased from the market. The lumps were crushed in boiling distilled water and then homogenized. The preparation was left to cool at $29^{\circ} \mathrm{C}$. It was then filtered through a $53 \mu \mathrm{m}$ mesh sieve, a piece of $45 \mu \mathrm{m}$ fine steel gauze and a piece of cotton fabric ( $25 \mu \mathrm{m}$ of fine-knit). The resulting suspension, called "kaolin milk", was left undisturbed for 3 days and protected from dust with a fine steel gauze. The particulates were recovered by draining of the water and they were placed in the sun to dry. The dried material was crushed in a porcelain mortar and the powder was sifted (53 $\mu \mathrm{m}$ mesh) and stored in a container away from moisture.

Paddy husk and coal ashes were collected from rice mills and brickfields respectively. The ashes were sieved with a fine net (mesh 600) and placed in an incubator for an hour at $60^{\circ} \mathrm{C}$ to dry up excessive moisture. Alluvial soil was collected from the riverbed of the Padma, Rajshahi. The china clay was procured from the local market. Both soil and clay were powdered in a mortar and pestle and finally meshed and dried. For comparison the insecticidal activity of the inert dusts, a commercial insecticide dust formulation "Sevin 85 SP" of Bayer CropScience was used.

\section{Experiments}

For combined treatment DE was mixed in different ratios with kaolin powder, paddy hush, coal ash, alluvial soil, china clay and carbaryl. The ratios were 1:1, 1:5, 1:10, 1:20, 1:50 and 1:100 for kaolin powder, ashes and clays and for carbaryl it was 1:1, 1:2, 1:5 and 1:10. In all cases the unit of DE was $50 \mathrm{ppm}$ excepting for carbaryl which was $5 \mathrm{ppm}$. The mixed formulations were used for the bioassay on the newly emerged adults of $C$. chinensis and $C$. maculatus with respective food and in each case a control batch was maintained on untreated food. The mortality of the beetles was recorded 24 and $48 \mathrm{~h}$ after treatment.

\section{Data analysis}

The mortality percentage was corrected using Abbott's formula (Abbott, 1925). Probit analysis was done according to Finney (1947) and Busvine (1971) using a software developed in the Department of Agricultural and Environmental Science, University of Newcastle upon Tyne, UK. Co-toxicity coefficients were calculated following Sun and Johnson (1960) as:

co-toxicity coefficient $=\frac{\text { IDSO of the toxicant alone }}{\text { LDSO of the toximant in the mixture }} \times 100$

\section{Results and Discussion}

The results of $L D_{50}, 95 \%$ confidence limits, regression equations $(Y)$ and $\chi^{2}$ of diatomaceous earth in mass ratio mixtures with tested dusts on C. chinensis and C. maculatus are presented in Table 1.

The $\mathrm{LD}_{50}$ and the co-toxicity coefficient for $\mathrm{DE}$ 
and dusts has been separated as ratios and are presented in Table 2. The result shows that the $\mathrm{LD}_{50}$ values of diatomaceous earth in mixture were decreased in different ratios as the different dusts were mixed. The synergism was in the order of DE: carbaryl $>\mathrm{DE}$ : china clay $>\mathrm{DE}$ : paddy hush ash> DE: coal ash> DE: alluvial soil> DE: kaolin powder at $24 \mathrm{~h}$ and DE: carbaryl> DE: paddy hush ash> DE: china clay> DE: coal ash> DE: alluvial soil> DE: kaolin powder at $48 \mathrm{~h}$ for $C$. chinensis and the synergism was in the order of $D E$ : carbaryl> DE: kaolin powder> DE: china clay> DE: paddy hush ash> DE: coal ash> DE: alluvial soil at 24 and $48 \mathrm{~h}$ for $C$. maculatus.

Table 1. $\mathrm{LD}_{50}, 95 \%$ confidence limits and regression equations of diatomaceous earth in mass ratio mixtures with tested dusts on adult pulse beetles.

\begin{tabular}{|c|c|c|c|c|c|c|}
\hline \multirow{2}{*}{$\begin{array}{l}\text { Pulse } \\
\text { beetles }\end{array}$} & \multirow{2}{*}{$\begin{array}{l}\text { Diatomaceous } \\
\text { earth: Dust }\end{array}$} & \multirow{2}{*}{$\begin{array}{c}\text { Combined } \\
\text { LD50 (ppm) }\end{array}$} & \multicolumn{2}{|c|}{ 95\% confidence limits } & \multirow{2}{*}{ Regression equation } & \multirow{2}{*}{$\chi^{2}(4 \mathrm{df})$} \\
\hline & & & Lower (ppm) & Upper (ppm) & & \\
\hline \multirow{14}{*}{ C. chinensis } & 24 hours & & & & & \\
\hline & Kaolin powder & 12703.57 & 2380.47 & 67793.47 & $Y=1.960363+0.7406656 X$ & 0.3381 \\
\hline & Paddy hush ash & 2432.78 & 1556.73 & 3801.82 & $Y=0.1815667+1.423003 X$ & 5.9025 \\
\hline & Coal ash & 3430.03 & 1486.49 & 7914.71 & $Y=1.966581+0.8580376 X$ & 0.3197 \\
\hline & Alluvial soil & 12563.47 & 911.16 & 173229.7 & $Y=3.228549+0.4321551 X$ & 0.0747 \\
\hline & China clay & 2242.81 & 1218.96 & 4126.62 & $Y=1.664071+0.9955641 X$ & 0.4389 \\
\hline & Carbaryl & 21.33 & 17.70 & 25.710 & $Y=0.1733399+3.631431 X$ & 2.4141 \\
\hline & 48 hours & & & & & \\
\hline & Kaolin powder & 859.36 & 449.24 & 1643.86 & $Y=2.835927+0.7375404 X$ & 1.1209 \\
\hline & Paddy hush ash & 274.00 & 151.06 & 496.99 & $Y=2.507756+1.022351 X$ & 3.0830 \\
\hline & Coal ash & 426.16 & 253.33 & 716.87 & $Y=2.298666+1.02729 X$ & 1.7954 \\
\hline & Alluvial soil & 652.29 & 296.75 & 1433.82 & $Y=3.301301+0.6035645 X$ & 0.5115 \\
\hline & China clay & 325.76 & 208.27 & 509.54 & $Y=1.698464+1.313831 X$ & 0.8225 \\
\hline & Carbaryl & 14.451 & 11.95 & 17.47 & $Y=0.5489369+3.837429 X$ & 4.1731 \\
\hline \multirow{14}{*}{ C. maculatus } & 24 hours & & & & & \\
\hline & Kaolin powder & 3643.651 & 1299.44 & 10216.85 & $Y=2.480977+0.7072854 X$ & 1.2359 \\
\hline & Paddy hush ash & 54946.68 & 2051.36 & 1471774 & $Y=2.156692+0.5998614 X$ & 0.2658 \\
\hline & Coal ash & 61029.04 & 686.56 & 5424904 & $Y=3.077287+0.4017759 X$ & 0.4222 \\
\hline & Alluvial soil & 61029.04 & 686.56 & 5424904 & $Y=3.077287+0.4017759 \times$ & 0.0422 \\
\hline & China clay & 4648.78 & 2040.53 & 10590.94 & $Y=1.317287+1.004192 X$ & 0.1762 \\
\hline & Carbaryl & 24.12 & 19.95 & 29.14 & $Y=0.0678453+3.567871 X$ & 2.4422 \\
\hline & 48 hours & & & & & \\
\hline & Kaolin powder & 503.74 & 301.46 & 841.763 & $Y=2.31615+0.9932041 X$ & 1.2084 \\
\hline & Paddy hush ash & 987.23 & 694.52 & 1403.312 & $Y=0.5533071+1.484992 X$ & 5.3390 \\
\hline & Coal ash & 3229.43 & 686.94 & 15182.06 & $Y=3.439218+0.444778 X$ & 0.2714 \\
\hline & Alluvial soil & 4265.59 & 978.81 & 18589.1 & $Y=3.09993+0.5234382 X$ & 0.4148 \\
\hline & China clay & 642.27 & 410.31 & 1005.385 & $Y=1.840817+1.125176 X$ & 1.6445 \\
\hline & Carbaryl & 15.47 & 12.85 & 18.614 & $Y=0.4231234+3.847742 X$ & 4.6092 \\
\hline
\end{tabular}

Table 2. Co-toxicity coefficient of mixtures of Diatomaceous earth in mass ratio mixtures with tested dusts on adult $C$. chinensis and C. maculatus

\begin{tabular}{|c|c|c|c|c|}
\hline Species & DE : Dust & Combined LD50 (ppm) & LD50 of DE in mixture (ppm) & Co-toxicity coefficient \\
\hline \multirow{14}{*}{ C. chinensis } & 24 hours & & & \\
\hline & Kaolin Powder & 12703.57 & 396.986 & 149.117 \\
\hline & Paddy Hush Ash & 2432.782 & 76.024 & 778.668 \\
\hline & Coal Ash & 3430.036 & 107.188 & 552.277 \\
\hline & Alluvial Soil & 12563.47 & 392.608 & 150.780 \\
\hline & China Clay & 2242.814 & 70.087 & 844.628 \\
\hline & Carbaryl & 21.33705 & 0.666 & 88885.150 \\
\hline & 48 hours & & & \\
\hline & Kaolin Powder & 859.3629 & 26.855 & 1546.838 \\
\hline & Paddy Hush Ash & 274.0051 & 8.562 & 4851.721 \\
\hline & Coal Ash & 426.1612 & 13.317 & 3119.348 \\
\hline & Alluvial Soil & 652.2975 & 20.384 & 2037.890 \\
\hline & China Clay & 325.7676 & 10.180 & 4080.585 \\
\hline & Carbaryl & 14.45133 & 0.451 & 92107.228 \\
\hline \multirow{14}{*}{ C. maculatus } & 24 hours & & & \\
\hline & Kaolin Powder & 3643.651 & 113.864 & 519.896 \\
\hline & Paddy Hush Ash & 54946.68 & 1717.083 & 34.475 \\
\hline & Coal Ash & 61029.04 & 1907.157 & 31.039 \\
\hline & Alluvial Soil & 61029.04 & 1907.157 & 31.039 \\
\hline & China Clay & 4648.786 & 145.274 & 407.488 \\
\hline & Carbaryl & 24.12017 & 0.753 & 78615.551 \\
\hline & 48 hours & & & \\
\hline & Kaolin Powder & 503.7491 & 15.742 & 2638.823 \\
\hline & Paddy Hush Ash & 987.2394 & 30.851 & 1346.483 \\
\hline & Coal Ash & 3229.436 & 100.919 & 411.620 \\
\hline & Alluvial Soil & 4265.599 & 133.299 & 311.632 \\
\hline & China Clay & 642.278 & 20.071 & 2069.670 \\
\hline & Carbaryl & 15.47023 & 0.483 & 86004.886 \\
\hline
\end{tabular}


In the present investigation the possibility of using $\mathrm{DE}$ as an extender or carrier for some other inert dusts or insecticidal dust formulations used to protect stored grain from insect attack. Formulations of this type would have the advantages of reducing levels of toxic residues and of having greater activity against insect populations with low levels of resistance to the chemical component of the formulation. Le Patourel and Singh (1984) showed that formulations of permethrin, cypermethrin and deltamethrin on absorptive silica had the additional advantage of a greater than additive action between the insecticidal components when tested against $T$. custaneum in grain of low moisture content.

The trials in the study indicate that SilicoSec can be used successfully as a protectant against adults of the bruchid beetles $C$. chinensis and $C$. maculatus. Regardless of the synergism of other factors, the effect of DE is dose-dependent (Fields \& Korunic, 2000; Athanassiou et al., 2003; Stathers et al., 2004; Mahdi \& Khalequzzaman, 2006), as in the case of residual insecticides used as grain protectants. However, the dose rate is more important in the case of inert dusts, given that the presence of dust in grain highly affects the physical properties of grain (Korunic et al., 1996). In addition, dust formulations that are effective at high application rates are usually not acceptable, for health and environmental reasons (Subramanyam \& Roesli, 2000). Nevertheless, higher application rates are recommended in cases of increased humidity, or as a surface treatment in bulked grain (Nickson et al., 1994; Bridgeman, 2000; Subramanyam \& Roesli, 2000; Cook \& Armitage, 2002).

In the present study, the rates of $1600 \mathrm{ppm}$ produced high mortality levels, though $100 \%$ was not achieved in most of the cases examined. However, given that pulse beetles can survive at application rates that are effective against other stored-grain beetle species (Aldryhim, 1990; Arthur, 2000a, b; Fields \& Korunic, 2000), higher dose rates or longer exposure intervals are needed to achieve $100 \%$ mortality for adults of this species. The efficacy of SilicoSec is determined by the type of the product the dust is applied to. Athanassiou et al. (2003), using SilicoSec in dose-response tests against $S$. oryzae adults in peeled rice, paddy rice, barley and maize, found that mortality notably varied in different types of grain.
The efficacy of diatomaceous earth on the mortality of insect pests of stored products is usually affected by several factors among which stands out the temperature (Chanbang et al., 2007). Generally, the increase in temperature favors the increase in the effectiveness of this product by stimulating the movement of insects within the grain mass, providing an increased contact of them, with the diatomaceous earth (Chanbang et al., 2007; Vayias et al., 2009). In addition, the insects have higher respiration rates at higher temperatures (Cotton, 1932), and consequently the greater water loss via spiracles promoting desiccation (Zachariassen, 1991). However, it was shown in some studies that the insect mortality can vary between species (Arthur, 2000a; Vayias \& Athanassiou, 2004; Athanassiou et al., 2005; Vayias et al., 2009).

Increased exposure time is highly important for DE efficacy, since surviving individuals may disperse from the treated substrate and colonize untreated parts of the product mass (Subramanyam \& Roesli, 2000). This fact must be seriously taken into account in cases of partially treated grain masses with $\mathrm{DE}$, such as the surface treatment in grain bulks, when DE in the surface is used alone, as a barrier to infestation (Korunic \& Mackay, 2000).

\section{Conclusion}

Diatomaceous earth is a potential alternative to be used in the development of strategies for management of resistance in insect pests of stored products, since a uniform response was observed among populations of $C$. chinensis and $C$. maculatus. In the present study, the rates of 1600 ppm produced high mortality levels, though $100 \%$ was not achieved in most of the cases examined. However, given that pulse beetles can survive at application rates that are effective against other stored-grain beetle species. Other dusts and clays used were inactive to $C$. chinensis and $C$. maculatus but in combination with DE they also provide some sort of synergistic effects.

\section{Ackowledgements}

Prof. Dr. Mahbub Hasan, Department of Zoology, University of Rajshahi, Bangladesh is acknowledged for supplying the Diatomaceous earth and members of the Crop Protection and Toxicology Laboratory for discussion. 


\section{References}

Abbott, W.S., 1925. A method of computing the effectiveness of an insecticide, J. Econ. Entomol. 18: 265-267.

Aldryhim, Y. N. 1990. Efficacy of the amorphous silica dust, Dryacide, against Tribolium confusum Duval and Sitophilus oryzae (L.) (Coleoptera: Tenebrionidae and Curculionidae). J. Stored Prod. Res. 26: 207-210.

Alves, L. F. A.; Buzarello, G. D.; Oliveira, D. G. P. and Alves, S. B. 2006. Ação da terra de diatomácea contra adultos do cascudinho Alphitobius diaperinus (Panzer, 1797) (Coleoptera: Tenebrionidae). Arquivos do Instituto Biológico, 73: 115-118.

Arthur, F.H. 2000a. Toxicity of diatomaceous earth to red flour beetles and confused flour beetles (Coleoptera: Tenebrionidae): effects of temperature and relative humidity. J. Econ. Entomol. 93: 526-532.

Arthur, F.H. 2000b. Impact of food source on survival of red flour beetles and confused flour beetles (Coleoptera: Tenebrionidae) exposed to diatomaceous earth. J. Econ. Entomol. 93: 1347-1356.

Athanassiou, C. G.; Vayias, B. J.; Dimizas, C. B.; Kavallieratos, N. G.; Papagregoriou, A. S. and Buchelos, C. T. 2005. Insecticidal efficacy of diatomaceous earth against Sitophilus oryzae (L.) (Coleoptera: Curculionidae) and Tribolium confusum du Val (Coleoptera: Tenebrionidae) on stored wheat: influence of dose rate, temperature and exposure interval. J. Stored. Prod. Res. 41: 47-55.

Athanassiou, C.G., Kavallieratos, N.G., Tsaganou, F.C., Vayias, B.J., Dimizas, C.B. \& Buchelos, C.Th. 2003. Effect of grain type on the insecticidal efficacy of SilicoSec against Sitophilus oryzae (L.) (Coleoptera: Curculionidae). Crop Prot. 22:1141-1147.

Beckel, H.; Lorini, I. and Lázzari, S. M. N. 2004. Comportamento de adultos de diferentes raças de Rhyzopertha dominica (Fabricius) (Coleoptera, Bostrichidae) em superfície tratada com deltamethrin. Rev. Brasileira de Entomol. 48:115-118.

Bridgeman, B.W. 2000. Application technology and usage patterns of diatomaceous earth in stored product protection. In: Zuxun, J., Quan, L., Yongsheng, L., Xianchiang, T., Lianghua, G. (Eds.), Proc. Seventh Intl. Working Conf. on Stored-Prod. Prot., Beijing, China, October 1998. Sichuan Publishing House of Science and Technology, Chengdu, Sichuan Province, pp. 785-789.

Busvine, J. R. 1971. A critical review of the techniques for testing insecticides. Commonwealth Agricultural Bureau: London, pp: 345.

Chanbang,Y.; Arthur, F. H.; Wilde, G. E. and Throne, J. E. 2007. Efficacy of diatomaceous earth to control Rhyzopertha dominica (F.) (Coleoptera: Bostrichidae) in rough rice: Impacts of temperature and relative humidity. Crop Prot. 26: 923-929.

Collins, D. A. 2006. A review of alternatives to organophosphorus compounds for the control of storage mites. J. Stored. Prod. Res. 42: 395-426.

Cook, D.A. \& Armitage, D.M. 2002. Integrated pest management for stored grain in the UK incorporating diatomaceous earths to prevent surface infestations of insects and mites. IOBC/WPRS Bulletin 25 (3): 221-229.
Cotton, R. T. 1932. The relation of respiratory metabolism of insects to their susceptibility to fumigants. J. Econ. Entomol. 25: 1088-1103.

Fields, P. \& Korunic, Z. 2000. The effect of grain moisture content and temperature on the efficacy of diatomaceous earths from different geographical locations against stored-product beetles. J. Stored Prod. Res. 36: 1-13.

Fields, P.G. 2000. Diatomaceous earth: advantages and limitations, pp. 781-784. In Zuxun, J., L. Quan, L. Yongsheng, T. Xianchang and G. Lianghua [eds.], 7th Intl. Working Conf. Stored-Prod. Prot., Sichuan Publishing House of Science \& Technology, Chengdu, Sichuan Province, Peoples Republic of China.

Finney, D.J., 1947. Probit Analysis: a statistical treatment of sigmoid response curve. Cambridge University Press, London, $333 \mathrm{pp}$.

Flinn, P. W. 1998. Temperature effects on efficacy of Choetospila elegans (Hymenoptera: Pteromalidae) to suppress Rhyzopertha dominica (Coleoptera: Bostrichidae) in stored wheat. J. Econ. Entomol. 91: 320-323.

Flinn, P. W. and Hagstrum, D. W. 2002. Temperature-mediated functional response of Theocolax elegans (Hymenoptera: Pteromalidae) parasitizing Rhyzopertha dominica (Coleoptera: Bostrichidae) in stored wheat. J. Stored. Prod. Res. 38: 185-190.

Korunic, Z. \& Mackay, A. 2000. Grain surface-layer treatment of diatomaceous earth for insect control. Arch. Ind. Hyg. Toxicol. 51: 1-11.

Korunic, Z. 1998. Review diatomaceous earths, a group of natural insecticides. J. Stored. Prod. Res. 34: 87-97.

Korunic, Z., Fields, P. G., Kovacs, M.I.P., Noll, J. S., Lukow, O. M., Demiank, C. J. \& Shibley, K. J. 1996. The effect of diatomaceous earth on grain quality. Postharvest Bio. Tech. 9: 373-387.

LaHue, D.W. 1978. Insecticidal dusts: grain protectants during high temperature-low humidity storage. J. Econ. Entomol. 71(2): 230-232.

Le Patourel, G. N. J. \& Singh, J. 1984. Toxicity of amorphous silicas and silica pyrethroids mixtures to Tribolium castaneum (Herbst) (Coleoptera: Tenebrionidae). J. Stored Prod. Res. 20: 183-190.

Li, Z. M.; Liu, S. S.; Liu, Y. Q. and Ye, G. Y. 2007. Temperaturerelated fitness costs of resistance to spinosad in the diamondback moth, Plutella xylostella (Lepidoptera: Plutelidae). Bull. Entomol. Res. 97: 627-635.

Mahdi, S. H. A. \& Khalequzzaman, M. 2006. Toxicity studies of some inert dusts with the cowpea beetle, Callosobruchus maculatus (Fabricius) (Coleoptera: Bruchidae). J. Biol. Sci. 6(2): 402-407.

Mckenzie, J. A. 1996. Selection Against Resistant Phenotypes. In: McKenzie, J. A. Ecological and evolutionary aspects of insecticide resistance, Austin: Academic Press, 185p.

McLaughlin, A. 1994. Laboratory trials on desiccant dust insecticides, pp. 638-645. In Highley, E., Wright, E. J., Banks, H. J. and Champ, B. R. [eds.], Proc. $6^{\text {th }}$ Intl. Working Conf. Stored-Prod. Prot., CAB International, Wallingford, Oxon, United Kingdom. 
Nickson, P.J., Desmarchelier, J.M. \& Gibbs, P. 1994. Combination of cooling with a surface application of Dryacide to control insects. In: Highley, E., Wright, E.J., Banks, H.J., Champ, B.R. (Eds.), Proc. Sixth Intl. Conf. on Stored-Prod. Prot., Canberra, Australia, April 1994, Vol. 2. $C A B$ International, Wallingford, Oxon, UK, pp. 646-649.

Stathers, T.E., Denniff, M. \& Golob, P. 2004. The efficacy and persistence of diatomaceous earths admixed with commodity against four tropical stored product beetle pests. J. Stored Prod. Res. 40: 113-123.

Subramanyam, B. \& Roesli, R. 2000. Inert dusts, pp. 321-379. In Subramanyam, B. and Hagstrum, D. W. (eds.), Alternatives to pesticides in stored-product IPM. Kluwer Academic Publishers, Boston, MA.

Sun, Y. P. \& Johnson, E. R. 1960. Analysis of joint action of insecticides against houseflies. J. Econ. Entomol., 53: 887-892.
Vayias, B. J. and Athanassiou, C. G. 2004. Factors affecting efficacy of the diatomaceous earth formulation SilicoSec against adults and larvae of the confused beetle Tribolium confusum du Val (Coleoptera: Tenebrionidae). Crop Prot. 23: 565-573.

Vayias, B. J.; Athanassiou, C. G. and Buchelos, C. T. 2009 Effectiveness of spinosad combined with diatomaceous earth against different European strains of Tribolium confusum du Val (Coleoptera: Tenebrionidae): Influence of commodity and temperature. J. Stored. Prod. Res. $\mathbf{4 5}$ 165-176.

Zachariassen, K. E. 1991. Routes of transpiratory water loss in a dryhabitat tenebrionid beetle. J. Expt. Biol. 157: 425-437. 